\title{
Реакция рынка на объявление о приобретении компаний открытого и закрытого типов
}

\author{
Чиркова Е.В. ${ }^{4}$, Чувствина Е.В. ${ }^{5}$
}

В статье представлены результаты исследования избыточной доходности в сделках по покупке открытых и закрытых компаний на развивающихся рынках капитала. В рамках исследования была проведена эмпирическая проверка зависимости избыточной доходности покупателя от факторов, влияющих на скидку при приобретении частной компании, $u$ размера «переплаты» за компанию-цель по сравнению со среднеотраслевыми мультипликаторами. Скидка при покупке закрытой компании определялась как разница между иеной сделки и иеной, рассчитанной исходя из средних мультипликаторов по публичным компаниям-аналогам. Кроме того, была проанализирована способность рынка отличать сделки с «ложной» мотивачией, в частности сделки, целью которых может являться распространение более высокого мультипликатора компании-покупателя на компанию-иель.

\section{JEL: $G 14, G 34$}

Ключевые слова: слияния и поглощения, закрытые компании, избыточная доходность, развивающиеся рынки капитала.

\section{Введение}

Слияния и поглощения (mergers and acquisitions - M\&A) являются распространенным инструментом стратегии развития компании, нацеленным на создание и усиление конкурентных преимуществ, получение операционной или финансовой синергии, повышение эффективности управления, использование налоговых выгод, снижение уровня риска объединенной компании, а также на получение выгоды от приобретения недооцененного актива или от продажи переоцененного.

Многочисленные исследования реакции рынка на объявление о приобретении публичных компаний (Jarrell and Poulsen, 1989; Jensen, 1986b; Schwert, 1996; Eckbo and Thorburn, 2000) показывают, что избыточная доходность (abnormal return) ${ }^{6}$ в окне вокруг даты сделки положительна для акций компаний-целей и отрицательна или близка к нулю для акций компаний-покупателей. Однако в последнее время появились работы, эмпирически подтверждающие разную реакцию рынка в сделках по покупке публичных и частных компаний: в последних акции компании-покупателя в среднем демонстрируют положительную избыточную доходность (Ang and Kohers, 2001; Bradley and Sundaram, 2004; Conn, Cosh, Guest and Hughes, 2003).

Вследствие этого представляется актуальным дальнейшее изучение реакции рынка на объявление о покупке частных и публичных компаний. Настоящая статья дополняет имеющиеся исследования по данному вопросу анализом влияния фактора «переплаты» ${ }^{7}$ за компанию-цель на благосостояние акционеров компании-покупателя при приобретении открытых и закрытых компаний на развивающихся рынках капитала. В отличие от более ранних работ, избыточная доходность покупателя рассчитывается как для короткого

\footnotetext{
${ }^{4}$ Канд. эконом. наук, доцент кафедры экономики и финансов фирмы НИУ ВШЭ.

${ }^{5}$ Аспирант кафедры экономики и финансов фирмы НИУ ВШЭ.

${ }^{6}$ Разница между фактическим приростом котировок акций и приростом, ожидаемым инвестором (может быть рассчитан, например, по модели оценки капитальных активов - САРМ).

${ }^{7}$ Под «переплатой» здесь и далее будем понимать покупку компании-цели по завышенной, по сравнению со средней в схожих сделках, цене.
} 
(классического), так и для более широкого окна события, что обусловлено более высокой вероятностью появления относительно ранних слухов о сделке на данных рынках.

\section{Анализ причин разницы в избыточной доходности при приобретении публичных и частных компаний}

Результаты, представленные в эмпирических работах, посвященных сравнению избыточной доходности при покупке частных и публичных компаний, схожи: избыточная доходность компании-покупателя при приобретении частной компании в среднем положительна, при покупке публичной - в среднем отрицательна или близка к нулю (Chang, 1998; Ang and Kohers, 2001; Fuller, Netter, Stegemoller, 2002; Moeller, Schlingemann, Stulz, 2004; Conn, Cosh, Guest and Hughes, 2003; Bradley and Sundaram, 2004; Faccio, McConnell and Stolin, 2004; Capron and Shen, 2007).

Более высокая избыточная доходность компании-покупателя при приобретении частной компании может быть связана с более низкой переплатой за компанию-цель, подтверждением чему служит более низкий мультипликатор «Цена/Чистая прибыль» (priceto-earnings, P/E), по которому покупаются закрытые компании (см. табл. 1).

Таблица 1

P/Е при покупке публичных и частных компаний в сделках, где покупатель и/или продавец являлись резидентами США

\begin{tabular}{|l|c|c|}
\hline $\begin{array}{c}\text { Год } \\
\text { сделки }\end{array}$ & $\begin{array}{c}\text { Р/E } \\
\text { (публичная } \\
\text { компания-цель) }\end{array}$ & $\begin{array}{c}\text { Р/E } \\
\text { (частная } \\
\text { компания-цель) }\end{array}$ \\
\hline 2000 & 18,0 & 16,0 \\
\hline 2001 & 16,7 & 15,3 \\
\hline 2002 & 19,7 & 16,6 \\
\hline 2003 & 21,2 & 19,4 \\
\hline 2004 & 22,6 & 19,0 \\
\hline 2005 & 24,4 & 16,9 \\
\hline 2006 & 23,7 & 21,4 \\
\hline 2007 & 24,9 & 21,6 \\
\hline
\end{tabular}

Источник: (Pratt, 2009).

Интересно проанализировать возможные причины разницы в избыточной доходности при покупке публичных и частных компаний.

\section{Применение скидки за низкую ликвидность}

В таблице 2 приведены размеры скидки за низкую ликвидность по данным разных исследователей: инвесторы готовы платить более высокую цену за более ликвидные активы; размер скидки при покупке актива с низкой ликвидностью варьирует в зависимости от метода исследования и характеристик выборки (в частности, временного интервала).

Таблица 2

Размер скидки за низкую ликвидность

\begin{tabular}{|c|c|c|c|c|}
\hline Исследование & $\begin{array}{c}\text { Определение скидки за } \\
\text { низкую ликвидность }\end{array}$ & Период & $\begin{array}{l}\text { Количест } \\
\text { во сделок }\end{array}$ & $\begin{array}{c}\text { Размер } \\
\text { скидки, \% }\end{array}$ \\
\hline $\begin{array}{l}\text { Исследования pre-IPO } \\
\text { (Emory and Dengel) }\end{array}$ & \begin{tabular}{|lrr} 
Разница & между & ценой \\
первичного & \multicolumn{2}{c}{ публичного } \\
размещения & (initial & public \\
offering - IPO) & и ценой сделки,
\end{tabular} & $\begin{array}{l}1997- \\
2000\end{array}$ & 266 & $\begin{array}{l}50 \text { (средняя), } \\
52 \text { (медиана) }\end{array}$ \\
\hline
\end{tabular}




\begin{tabular}{|c|c|c|c|c|}
\hline & закрытой за 5 месяцев до IPО & & & \\
\hline $\begin{array}{l}\text { Исследования Business } \\
\text { Valuation Resources LLC }\end{array}$ & $\begin{array}{l}\text { Разница между ценой IPO и } \\
\text { котировками конвертируемых } \\
\text { привилегированных акций или } \\
\text { опционов на обыкновенные } \\
\text { акции до IPO }\end{array}$ & $\begin{array}{l}1999- \\
2007\end{array}$ & $\begin{array}{c}873 \\
\text { (сделки за } \\
1-2 \text { года } \\
\text { до IPO) }\end{array}$ & $\begin{array}{c}65,8 \\
\text { (медиана) }\end{array}$ \\
\hline $\begin{array}{ll}\text { Исследования } & \text { акций } \\
\text { ограниченного } \\
\text { обращения } \quad \text { (restricted } \\
\text { stock) } & \text { Columbia } \\
\text { Financial Advisors }\end{array}$ & $\begin{array}{l}\text { Разница между котировками } \\
\text { обыкновенных акций и ценой } \\
\text { сделки c c } 2 \text { акциями } \\
\text { ограниченного обращения }\end{array}$ & $\begin{array}{c}1997- \\
1998\end{array}$ & 15 & $\begin{array}{c}13 \text { (средняя), } \\
9 \text { (медиана) }\end{array}$ \\
\hline $\begin{array}{lr}\text { Исследования } & \text { акций } \\
\text { ограниченного } \\
\text { обращения } \\
\text { компании } & \text { оценочнй } \\
\text { Opinions Inc. } & \text { FMV } \\
\end{array}$ & $\begin{array}{l}\text { Разница между котировками } \\
\text { обыкновенных акций и ценой } \\
\text { сделки с с } \quad \text { акциями } \\
\text { ограниченного обращения с } \\
\text { периодом владения 1 год }\end{array}$ & $\begin{array}{l}1997- \\
2005\end{array}$ & 229 & $\begin{array}{l}22 \text { (средняя), } \\
18 \text { (медиана) }\end{array}$ \\
\hline $\begin{array}{l}\text { Исследование частных } \\
\text { размещений (Oliver and } \\
\text { Meyers) }\end{array}$ & $\begin{array}{l}\text { Разница между рыночными } \\
\text { котировками и ценой частного } \\
\text { размещения акций }\end{array}$ & $\begin{array}{l}1980- \\
2000\end{array}$ & 59 & $\begin{array}{c}27,4 \\
\text { (средняя), } \\
24,8 \\
\text { (медиана) }\end{array}$ \\
\hline
\end{tabular}

Источник: (Pratt, 2009).

В работе А. Дамодарана (Damodaran, 2005) выделяются следующие факторы, влияющие на скидку за низкую ликвидность частной компании-цели:

1. Ликвидность активов: компанию с высокой долей ликвидных активов проще реализовать, целиком или по частям.

2. Финансовое положение: прибыльную компанию, генерирующую стабильный денежный поток, проще продать, чем убыточное предприятие.

3. Возможность выведения компании на IPO: если собственники компании-цели имеют возможность быстро провести размещение, то есть сделать акции ликвидными, то компания будет торговаться с меньшей скидкой за неликвидность.

4. Тип покупателя: для стратегического инвестора, не преследующего цель последующей продажи компании, скидка за низкую ликвидность ниже; для финансового инвестора, приобретающего компанию с целью ее перепродажи целиком или по частям, скидка за низкую ликвидность выше.

5. Размер компании: крупные компании, как правило, имеют длинную операционную историю, налаженные контакты с поставщиками и каналы сбыта, узнаваемый бренд, регулярно обновляемые операционные и финансовые планы, что делает их относительно более ликвидными.

6. Приобретаемая доля: чем она больше, тем выше вероятность того, что компания покупается в стратегических целях, и, следовательно, скидка за низкую ликвидность меньше. С другой стороны, поскольку круг стратегических инвесторов ограничен, с увеличением покупаемой доли в компании-цели скидка за низкую ликвидность может увеличиться ${ }^{8}$.

7. Состояние рынка: скидка за низкую ликвидность непостоянна во времени и варьирует с изменением активности рынка и спроса на ликвидные активы.

\footnotetext{
${ }^{8}$ При этом также будет расти и премия за контроль. Конечный выигрыш покупателя при этом определяется соотношением изменения скидки за низкую ликвидность и премии за контроль, а значит, может иметь любой знак.
} 


\section{Различия в мотивации при поглощении открытых и закрытых компаний}

Переплата при покупке публичной компании часто объясняется мотивацией покупателя. Согласно вирусной гипотезе (hubris hypothesis), менеджеры компаниипокупателя переплачивают за компанию-цель, поскольку искренне верят, что способны лучше руководить ею, нежели менеджеры покупаемой компании (Roll, 1986). В соответствии с гипотезой свободного денежного потока (free cash flow hypothesis), менеджеры компаниипокупателя могут заплатить неоправданно высокую цену за компанию-цель в стремлении руководить «империей» (Jensen, 1986a) ${ }^{9}$.

Однако, по мнению западных ученых, при приобретении частной компании данные мотивы выражены слабее по следующим причинам. Переговоры по покупке частной компании характеризуются большей закрытостью, их инициирование или прекращение не сопровождаются «издержками потери престижа» потенциального покупателя; как следствие, в сделках по покупке частных компаний «вирусное» поведение проявляется в меньшей степени (Kohers, 2004). Маловероятно и то, что менеджмент будет использовать частные компании для построения «империй»: этой цели быстрее достичь через приобретение в среднем больших по размеру публичных компаний. На наш взгляд, с первым утверждением можно согласиться, а вот последнее является спорным: если закрытые компании дешевле, то в рамках одного и того же бюджета можно купить бизнес большего размера.

\section{Форма оплаты сделки}

Избыточная доходность покупателя при приобретении публичных и частных компаний зависит от условий сделки, в частности от формы оплаты (см. табл. 3).

Таблица 3

Избыточная доходность акций компании-покупателя в разрезе форм оплаты

\begin{tabular}{|c|c|c|c|c|}
\hline \multirow[b]{2}{*}{ Исследование } & \multicolumn{2}{|c|}{$\begin{array}{c}\text { Покупка частных } \\
\text { компаний }\end{array}$} & \multicolumn{2}{|c|}{$\begin{array}{c}\text { Покупка публичных } \\
\text { компаний }\end{array}$} \\
\hline & $\begin{array}{l}\text { Оплата } \\
\text { акцияями }\end{array}$ & $\begin{array}{c}\text { Оплата } \\
\text { денежными } \\
\text { средствами }\end{array}$ & $\begin{array}{l}\text { Оплата } \\
\text { акцุиями }\end{array}$ & $\begin{array}{c}\text { Оплата } \\
\text { денежныли } \\
\text { средствами }\end{array}$ \\
\hline Чанг (Chang, 1998) & $+2,64 \% * * *$ & $+0,09 \%$ & $-2,46 \% * * *$ & $-0,02 \%$ \\
\hline $\begin{array}{l}\text { Анг и Кохерс (Ang and } \\
\text { Kohers, 2001) }\end{array}$ & $+1,32 \% * * *$ & $+1,825 \% * * *$ & $-1,26 \% * * *$ & $+0,62 \%$ \\
\hline $\begin{array}{l}\text { Моэллер, Шлингеманн, } \\
\text { Штульц (Moeller, } \\
\text { Schlingemann, Stulz, 2004) }\end{array}$ & $+1,493 \% * * *$ & $+1,208 \% * * *$ & $-2,023 \% * * *$ & $+0,364 \%$ \\
\hline $\begin{array}{l}\text { Фуллер, Неттер, } \\
\text { Штегемоллер (Fuller, Netter, } \\
\text { Stegemoller, 2002) }\end{array}$ & $+2,43 \% * * *$ & $+1,62 \% * * *$ & $-1,86^{* *}$ & $+0,34 \%$ \\
\hline $\begin{array}{l}\text { Брэдли и Сундарам (Bradley } \\
\text { and Sundaram, 2004) }\end{array}$ & $+1,39 \% * * *$ & $+0,71 \% * * *$ & $-1,29 \% * * *$ & $+0,83 * * *$ \\
\hline $\begin{array}{l}\text { Фачио, МакКоннел и } \\
\text { Штолин (Faccio, McConnell } \\
\text { and Stolin, 2004) }\end{array}$ & $+3,90 \% * * *$ & $+1,17 \% * * *$ & $-1,81 \% * *$ & $+0,3 \%$ \\
\hline
\end{tabular}

\footnotetext{
${ }^{9}$ Вирусная гипотеза и гипотеза свободного денежного потока, строго говоря, являются разными гипотезами: в первом случае менеджеры надеются, что создадут стоимость для акционеров, хотя и заблуждаются на этот счет, во втором случае такая задача не ставится менеджерами изначально.
} 
Как следует из таблицы 3, при покупке частной компании избыточная доходность акций покупателя положительна и значима для всех форм оплаты, при этом она выше при оплате акциями. В сделках по приобретению публичных компаний с оплатой акциями избыточная доходность покупателя значимо отрицательна, с оплатой денежными средствами - практически во всех случаях положительна, хотя и незначима.

Как показано в работах Майерса и Мэйлуфа (Myers and Mayluf, 1984) и Шлейфера и Вишны (Shleifer and Vishny, 2003), инвесторы воспринимают использование акций покупателя в качестве средства платежа при приобретении публичной компании как сигнал об их переоценке. Согласно работе Чанга (Chang, 1998) и Дрейпера и Паудяла (Draper and Paudyal, 2008), при покупке частной компании, напротив, оплата акциями воспринимается рынком как положительный сигнал: один или несколько собственников частной компании, в отличие от распыленных акционеров публичной компании, в случае оплаты акциями мотивированы на детальную проверку операционной и финансовой деятельности компаниипокупателя и не примут в оплату переоцененные бумаги.

На избыточную доходность продавца при оплате сделки акциями (независимо от типа компании-цели) положительно влияет возможность отсрочки уплаты налога на прирост капитала, поскольку оплата акциями трактуется как мена и налоговое обязательство не возникает до момента продажи акций. Влияние этого фактора может частично нивелироваться тем, что акции менее ликвидны, чем деньги. Риск ликвидности возникает, например, при запрете на продажу пакета в течение определенного срока или из-за падения цены при продаже большого пакета. Как следствие, собственники компании-цели могут согласиться на большую скидку при оплате сделки денежными средствами.

\section{Прочие факторы}

Разница в избыточной доходности при покупке частной и публичной компании может объясняться реакцией рынка на диверсификацию, а также распознаванием ложного мотива сделки по натягиванию мультипликатора компании-покупателя на финансовые показатели компании-цели (bootstrapping).

Исследования диверсификации не ведут к единому выводу относительно ее влияния на стоимость компании. На развитых рынках капитала есть свидетельства как создания (Villalonga, 2000, Bohl and Pal, 2006), так и разрушения (Lang and Stulz, 1994, Berger and Ofek, 1995) стоимости компании посредством диверсификации. В частности, внутренний рынок капитала - одно из классических «оправданий» диверсификации - не всегда эффективен при распределения финансовых ресурсов вследствие сохраняющейся информационной асимметрии между менеджерами разных уровней (Berger and Ofek, 1995). Однако на развивающихся рынках капитала диверсифицированные структуры могут восполнять функции институтов, способствуя эффективному распределению продуктовых, человеческих и финансовых ресурсов (Fauver, Houston and Naranjo, 2003).

Натягивание высокого мультипликатора компании-покупателя может произойти при приобретении компанией с высоким $\mathrm{P} / \mathrm{E}$ цели с низким $\mathrm{P} / \mathrm{E}$, в результате чего объединенная компания (включающая активы покупателя и цели) будет котироваться по более высокому мультипликатору, чем компания-цель. Иными словами, несмотря на то, что способность генерировать денежный поток компании-цели не меняется, после сделки рынок может переоценить ее активы и финансовые результаты. Однако в реальной жизни рынок, как правило, распознает этот мотив и корректирует котировки компании-покупателя после сделки до справедливого уровня.

\section{Методология расчета избыточной доходности}

Анализ краткосрочной реакции рынка на объявление о сделке проводился с использованием метода анализа события (event study) через анализ отклонения наблюдаемой 
доходности акций компании-покупателя в момент объявления об М\&А от «нормальной» доходности, ожидаемой инвесторами при отсутствии сделки. Расчет «нормальной» доходности проводился в соответствии с моделью рыночного индекса, согласно которой доходность акций котируемой компании при условии отсутствия «события» (сделки) ожидается на уровне доходности рынка в целом.

Избыточная доходность рассчитывалась для следующих окон: (-1; +1) (Moeller, Schlingemann, Stulz, 2004; Conn, Cosh, Guest and Hughes, 2003) и (-2; +2) (Fuller et al., 2002; Bradley and Sundaram, 2004), где 0 - это дата объявления о сделке. Применение узких окон ($1 ;+1)$ и $(-2 ;+2)$ позволяет решить проблему влияния других новостей о компании на колебание цен акций.

С учетом того что сделки (особенно с участием публичных компаний) могут ожидаться рынком, применение узкого окна ведет к недооценке реакции на объявление о сделке. Согласно данным базы Zephyr (Bureau van Dijk), в исследуемом периоде слухи о сделке появлялись в среднем за 30 дней до ее объявления. Для учета влияния слухов избыточная доходность покупателя рассчитывалась также для окна $(-30 ;+1)$, где 0 - дата объявления о сделке.

Мы использовали следующий алгоритм расчета кумулятивной избыточной доходности (CAR):

(a) расчет доходности акций компании-покупателя/индекса за каждый день в окне наблюдения:

$$
R_{T}=\frac{P_{T}-P_{T-1}}{P_{T-1}},
$$

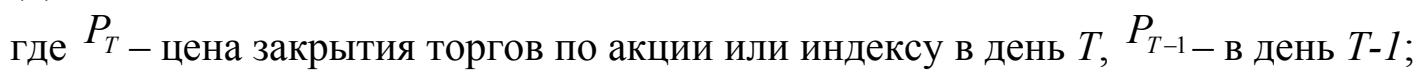

(б) расчет избыточной доходности акций компании-покупателя за каждый день в окне наблюдения:

$$
A R_{i}^{T}=R_{i}^{T}-R_{m}^{T}
$$

где $R_{i}^{T}$ - доходность акций покупателя, $R_{m}^{T}$ - доходность индекса;

(в) расчет кумулятивной избыточной доходности в окне наблюдения:

(3)

$$
C A R_{i}^{(x ; y)}=\sum_{T=x}^{y} A R_{i}^{T},
$$

где (х; у) - продолжительность окна.

После расчета кумулятивной избыточной доходности для подвыборок сделок с частными и публичными компаниями с помощью $t$-статистики была проведена проверка отличия среднего значения избыточной доходности в разрезе типов сделок (покупка частной или публичной компании) от нуля. Среднее значение избыточной доходности по конкретным подвыборкам использовалось для проверки гипотез.

\section{Эмпирическое исследование избыточной доходности при покупке публичных и частных компаний на развивающихся рынках капитала}

\section{Характеристики выборки}

В качестве основного источника информации для получения данных о сделках и финансовых показателях компаний-участниц использовалась базы данных BLOOMBERG PROFESSIONAL ${ }^{\circledR}$, Zephyr (Bureau van Dijk) и Capital IQ (Standard \& Poors). Для исследования были отобраны завершенные сделки, которые в системе BLOOMBERG PROFESSIONAL ${ }^{\circledR}$ классифицируются как Company Takeover, Tender offer и Majority Stake Purchase, в базе данных Zephyr - как Merger и Acquisition.

Для формирования выборки применялись следующие фильтры: 
1. Страновой разрез: выборка состоит из сделок на внутренних рынках ${ }^{10}$ по развивающимся странам, входящим в индекс развивающихся стран «Морган Стенли» (Morgan Stanley Emerging Markets Index), который включает Россию ${ }^{11}$.

2. Временной разрез: сделки за период с 1 января 2000 года по 1 апреля 2008 года.

3. Отраслевой разрез: сделки во всех отраслях, кроме финансового сектора, коммунальных услуг и недвижимости, что является стандартной практикой в аналогичных исследованиях (Fuller et al., 2002).

4. Приобретаемая доля: сделки, до которых доля владения компании-покупателя в компании-цели была ниже 15\%, а после превысила 50\%. Применение данного фильтра позволяет исключить сделки, где высокая первоначальная доля владения покупателя практически исключает возможность появления иного стратегического инвестора, а также сделки, по которым не происходит переход контроля над компанией-целью.

Общее количество наблюдений в выборке составляет 128, в том числе 84 сделки по приобретению компаний закрытого типа (из них 14 российских) и 44 сделки по покупке компаний открытого типа (из них одна российская). В 118 сделках приобретаемая доля была равна или превысила 50\%.

\section{Гипотезы, проверяемые в рамках эмпирического исследования}

Гипотеза 1. На развивающихся рынках капитала избыточная доходность покупателя при приобретении частных компаний выше, чем при приобретении публичных компаний.

В рамках данной гипотезы сравниваются значения и статистическая значимость избыточной доходности при приобретении публичных и частных компаний.

Гипотеза 2. Более высокая избыточная доходность при покупке частных компаний по сравнению с покупкой публичных компаний объясняется более низкой оценкой компаниицели.

Для проверки данной гипотезы тестируется зависимость избыточной доходности компании-покупателя от факторов, влияющих на недооценку при покупке частных компаний: 1) факторы, влияющие на скидку за неликвидность, а именно финансовое положение компании-цели, приобретаемая доля, активность рынка корпоративного контроля; 2) ликвидность средства платежа; 3) прочие факторы: диверсификационная сделка или нет.

Гипотеза 3. Избыточная доходность покупателя в сделках M\&A выше, если компанияцель приобретается по мультипликатору ниже среднеотраслевого, и ниже в обратном случае.

В рамках данной гипотезы реакция рынка на ценовой компонент сделки проверяется, исходя из соотношения мультипликатора $\mathrm{P} / \mathrm{E}$ компании-цели и аналогичного среднеотраслевого мультипликатора, рассчитанного по развивающимся рынкам в году совершения сделки ${ }^{12}$. Средняя избыточная доходность сравнивается по двум подвыборкам сделок: 1) где мультипликаторы компании-цели выше среднеотраслевого значения (такие сделки классифицируются как сделки с «переплатой») и 2) где мультипликаторы компаниицели ниже или соответствуют среднеотраслевым мультипликаторам (сделки с «недоплатой»).

Гипотеза 4. Избыточная доходность покупателя в сделках M\&A тем ниже, чем больше отношение Р/Е покупателя к Р/Е цели, поскольку рынок негативно реагирует на

\footnotetext{
10 Сделками на внутренних рынках считаются сделки, в которых компания-покупатель и компания-цель осуществляют операционную деятельность в одной стране.

11 В период проведения исследования данный индекс включал 25 стран: Аргентину, Бразилию, Чили, Китай, Колумбию, Чешскую Республику, Египет, Венгрию, Индию, Индонезию, Израиль, Иорданию, Корею, Малайзию, Мексику, Марокко, Пакистан, Перу, Филиппины, Польшу, Россию, Южную Африку, Тайвань, Таиланд и Турцию.

${ }^{12}$ Из рассмотрения исключаются сделки, по которым мультипликатор Р/Е компании-цели отрицателен в силу убыточности покупаемой компании.
} 
«натягивание» высокого мультипликатора покупателя на финансовые показатели компаниицели.

В рамках данной гипотезы проверяется разница в избыточной доходности по двум группам сделок: 1) с более высоким мультипликатором Р/Е компании-покупателя по сравнению с компанией-целью; 2) с более низким мультипликатором. Также строится регрессия зависимости избыточной доходности покупателя от отношения Р/Е покупателя к $\mathrm{P} / \mathrm{E}$ компании-цели. Более низкая избыточная доходность для первой группы сделок и отрицательный коэффициент при зависимой переменной в регрессии могут говорить о способности рынка отличать сделки с ложной мотивацией от сделок, нацеленных на создание дополнительной стоимости.

Результаты эмпирического исследования

Проверка гипотезы 1

Таблица 4

Избыточная доходность при покупке частных и публичных компаний

\begin{tabular}{|c|c|c|c|}
\hline & $\operatorname{CAR}(-1 ;+1)$ & $\operatorname{CAR}(-2 ;+2)$ & $\operatorname{CAR}(-30 ;+1)$ \\
\hline $\begin{array}{c}\text { Частная } \\
\text { компания- } \\
\text { цель }\end{array}$ & $1,97 \% * * *$ & $2,51 \% * * *$ & $6,48 \% * * *$ \\
\hline$t$-st. & 3,022 & 3,007 & 3,898 \\
\hline $\begin{array}{c}\text { Публичная } \\
\text { компания- } \\
\text { цель }\end{array}$ & $-0,30 \%$ & $-1,05 \%$ & $2,23 \%$ \\
\hline$t-s t$ & $-0,302$ & $-0,834$ & 0,590 \\
\hline Вся выборка & $1,21 \% * *$ & $1,29 \% *$ & $5,02 \% * * *$ \\
\hline$t-s t$ & 2,180 & 1,814 & 2,958 \\
\hline
\end{tabular}

Избыточная доходность покупателя при приобретении частных компаний значимо положительна для всех окон наблюдения, тогда как при приобретении публичных компаний - незначима и отрицательна для окон $(-1 ;+1)$ и $(-2 ;+2)$ (см. табл. 4). Таким образом, эмпирическая проверка подтверждает, что рынок по-разному реагирует на сделки по приобретению публичных и частных компаний, более благосклонно оценивая приобретение последних.

На развивающихся рынках капитала в окне наблюдения $(-1 ;+1)$ избыточная доходность покупателя составляет $+1,97 \%$ и $-0,3 \%$ при приобретении частных и публичных компаний соответственно (см. табл. 4). Для сравнения: на развитых рынках капитала в окне наблюдения (-1; +1) избыточная доходность покупателя при приобретении частной компании ниже и составляет $+1,5 \%$ в работе Моэллер, Шлингеманна, Штульца (Moeller, Schlingemann, Stulz, 2004) и $+1,05 \%$ в работе Конна, Коша, Гуэста и Хьюза (Conn, Cosh, Guest and Hughes, 2003). При этом покупка публичных компаний характеризуется более сильной отрицательной реакцией рынка: $-1,02 \%$ и $-0,99 \%$ в указанных работах соответственно.

Более сильную положительную реакцию рынка при покупке частных компаний и более слабую отрицательную при приобретении публичных можно объяснить тем, что развивающиеся рынки характеризуются большей волатильностью и, соответственно, должны обеспечивать большую доходность вложений как компенсацию за больший инвестиционный 
риск. С другой стороны, поскольку избыточная доходность есть индикатор того, насколько, по мнению рынка, завышена цена покупки, полученный результат может свидетельствовать о том, что на развивающихся рынках покупатели меньше переплачивают, в силу, например, меньшей конкуренции на рынке M\&A.

В более широком окне $(-30 ;+1)$ избыточная доходность покупателей публичных и частных компаний положительна, хотя в сделках по покупке публичных компаний незначима. Этот результат можно трактовать как свидетельство того, что основная реакция рынка на сделку приходится на момент, когда появляются первые слухи. Подтверждением этому служит и незначимость разницы в избыточной доходности при покупке публичных и частных компаний для окна $(-30 ;+1)$, вследствие чего нельзя отклонить гипотезу о том, что избыточная доходность покупателя как при приобретении частных, так и при приобретении публичных компаний положительна.

\section{Проверка гипотезы 2}

Оцениваются параметры эконометрической модели следующего вида:

$$
C A R^{a c q}=\alpha_{1} \cdot R O E^{t \text { arg } e t}+\alpha_{2} \cdot \text { Interest }+\alpha_{3} \cdot \text { Payment }+\alpha_{4} \cdot \text { Deals }+\alpha_{5} \cdot \text { Diver },
$$

где:

$R O E^{\text {target}}-$ доходность собственного капитала компании-цели: отношение прибыли после налогообложения к рыночной стоимости собственного капитала, рассчитанной по цене сделки. Данный показатель вводится как прокси ожиданий инвестора относительно отдачи на вложенные средства;

Interest - доля, приобретенная покупателем в результате сделки. Данный показатель призван отражать разницу возможностей влиять на стратегические решения компаний. Можно предположить, что аккумулирование контрольного пакета, позволяющего влиять на решения компании-цели, при отсутствии переплаты будет положительно оцениваться рынком;

Payment - дамми-переменная, принимающая значение 0, если сделка оплачена денежными средствами, долгом или их комбинацией, и 1 , если сделка оплачена только акциями или комбинаций денежных средств и акций;

Deals - количество сделок в данном году в отрасли компании-цели как прокси активности рынка;

Diver - дамми-переменная, принимающая следующие значения: 0, если компания-цель принадлежит к той же отрасли, что и компания-покупатель, и 1 в противном случае. Переменной Diver присваивается значение 0, если у участников сделки одинаковые первые две цифры SIC-кода или Industry Classification Benchmark (отраслевая классификация, используемая в базе данных Zephyr). При отсутствии этих данных схожесть сферы деятельности участников сделки определяется исходя из описаний компаний.

Таблица 5

Результаты тестирования зависимости избыточной доходности от факторов, влияющих на меньшую переплату при покупке закрытой компании

\begin{tabular}{c|ccc} 
& CAR $(-1 ;+1)$ & CAR $(-2 ;+2)$ & CAR $(-30 ;+1)$ \\
\hline ROE & $-0,013$ & $-0,012$ & $-0,015$ \\
$t$-st & $-1,30$ & $-0,98$ & $-0,61$ \\
& & & \\
Interest & $\mathbf{0 , 0 7 5 * *}$ & 0,049 & 0,069 \\
$t$-st & 2,43 & 1,23 & 0,88 \\
& & & \\
Payment & 0,0072 & 0,011 & $\mathbf{0 , 0 0 8 * *}$
\end{tabular}




\begin{tabular}{c|ccc}
$t$-st & 0,47 & 0,53 & 2,09 \\
Deals & $-0,0014$ & $-0,0003$ & $-0,0047$ \\
$t$-st & $-0,42$ & $-0,07$ & $-0,54$ \\
& & & \\
Div & $-0,001$ & $-0,011$ & $-0,028$ \\
$t$-st & $-0,07$ & $-0,55$ & $-0,73$ \\
& & & \\
Cons & $-0,037$ & $-0,014$ & 0,014 \\
$t$-st & $-1,42$ & $-0,42$ & 0,21 \\
& & & \\
F- & 1,59 & 0,67 & 1,37 \\
statistics & *** результат значим на 1\%-ном уровне \\
** результат значим на 5\%-ном уровне \\
* результат значим на 10\%-ном уровне
\end{tabular}

Как следует из таблицы 5, влияние доходности собственного капитала компании-цели на избыточную доходность покупателя отрицательно и незначимо, что можно объяснить так: чем ниже ожидаемая инвестором отдача на вложенные средства, тем большую скидку за неликвидность можно применить в отношении цели и тем выше будет избыточная доходность.

Значение переменной «приобретаемая доля» положительно для всех анализируемых окон события, а для окна $(-1 ;+1)$ - положительно и значимо. Это подтверждает, что на развивающихся рынках аккумулирование контрольного пакета не сопровождается уплатой необоснованно высокого вознаграждения, что и объясняет рост избыточной доходности с ростом приобретаемой доли.

Значение переменной «способ оплаты» положительно для всех трех окон и значимо для окна $(-30 ;+1)$, то есть рынок выше оценивает сделки по покупке частных компаний с оплатой акциями или комбинацией денежных средств и акций. Таким образом, реакция рынка на покупку закрытых компаний с оплатой акциями схожа (с точки зрения знаков) на развитых и развивающихся рынках (см. табл. 3 для развитых рынков). Возможно, это связано с тем, что оплата сделки по покупке закрытой компании акциями может восприниматься рынком как положительный сигнал о том, что акции компании-покупателя справедливо оценены. Кроме того, при оплате сделки акциями, в отличие от оплаты денежными средствами, у собственников компании-цели не возникают обязательства по уплате налогов; в частности, по российскому законодательству налоговая база возникает только при последующей реализации ценных бумаг на рынке.

Переменная «активность рынка», определяемая как количество сделок в отрасли компании-цели в году, когда было объявлено о сделке, отрицательна и незначима для всех трех исследуемых окон. Отрицательный коэффициент подтверждает, что в годы высокой активности рынка корпоративного контроля в силу высокого спроса на активы скидка за неликвидность и, следовательно, избыточная доходность ниже.

Переменная «диверсификация» отрицательна и незначима для всех анализируемых окон. Данный результат подтверждает (с точки зрения знаков) отрицательную реакцию рынка на степень информационной асимметрии и ожидаемые в перспективе трудности по управлению приобретенной компанией в силу отсутствия опыта ведения деятельности в новой отрасли.

Поскольку большая часть сделок в выборке характеризовалась приобретением $50 \%$ или более в компании-цели, можно считать подтвердившимся предположение о том, что при стратегических покупках скидки за неликвидность нет. Таким образом, большая избыточная 
доходность при приобретении частных компаний, по сравнению с приобретением публичных, на анализируемой выборке объясняется другими факторами.

Проверка гипотезы 3

Таблица 6

Избыточная доходность по сделкам с «переплатой» и «недоплатой», где факт «переплаты» определяется по мультипликатору $\mathrm{P} / \mathrm{E}$

\begin{tabular}{c|ccc} 
& CAR $(-1 ;+1)$ & CAR $(-2 ;+2)$ & CAR $(-30 ;+1)$ \\
\hline \multirow{3}{*}{ Недоплата } & $2,38 \% * * *$ & $2,42 \% * *$ & $5,74 \% * * *$ \\
$t$-st & 3,0854 & 2,597 & 2,910 \\
& \multicolumn{4}{|}{} \\
Переплата & $0,70 \%$ & $1,37 \%$ & $7,67 \% * *$ \\
$t$-st & 0,6335 & 1,371 & 2,178 \\
*** результат значим на 1\%-ном уровне \\
** результат значим на 5\%-ном уровне \\
* результат значим на 10\%-ном уровне
\end{tabular}

Таблица 7

Избыточная доходность компании-покупателя по сделкам с «переплатой» и «недоплатой» при приобретении частных компаний

\begin{tabular}{c|ccc} 
& CAR $(-1 ;+1)$ & $\mathrm{CAR}(-2 ;+2)$ & $\mathrm{CAR}(-30 ;+1)$ \\
\hline \multirow{3}{*}{ Недоплата } & $2,74 \% * *$ & $3,44 \% * * *$ & $6,21 \% * *$ \\
$t$-st & 2,7081 & 2,736 & 2,327 \\
& & & \\
Переплата & $1,53 \%$ & $2,26 \%$ & $9,63 \% * *$ \\
$t$-st & 0,9655 & 1,545 & 2,797 \\
*** результат значим на $1 \%$-ном уровне \\
** результат значим на $5 \%$-ном уровне \\
* результат значим на $10 \%$-ном уровне
\end{tabular}

Таблица 8

Избыточная доходность компании-покупателя по сделкам с «переплатой» и «недоплатой» при приобретении публичных компаний

\begin{tabular}{c|ccc} 
& CAR $(-1 ;+1)$ & CAR $(-2 ;+2)$ & CAR $(-30 ;+1)$ \\
\hline \multirow{2}{*}{ Недоплата } & $1,63 \%$ & $0,25 \%$ & $4,75 \% *$ \\
$t$-st & 1,4541 & 0,249 & 1,883 \\
& & & \\
Переплата & $-0,73 \%$ & $-0,18 \%$ & $4,27 \%$ \\
$t$-st & $-0,5813$ & $-0,201$ & 0,555 \\
*** результат значим на 1\%-ном уровне & \\
** результат значим на 5\%-ном уровне & \\
* результат значим на 10\%-ном уровне &
\end{tabular}

Как следует из таблиц 7 и 8, избыточная доходность при покупке частных и публичных компаний выше в сделках с «недоплатой», что подтверждает проверяемую гипотезу. При покупке публичных компаний избыточная доходность незначима для окон $(-1 ;+1)$ и $(-2 ;+2)$, но положительна и значима для окна $(-30 ;+1)$ в случае покупки по заниженным, по 
сравнению с рынком, мультипликаторам. В целом рынок способен отличить «хорошую» компанию-цель от «плохой» и понимает, что за «хорошую» компанию надо платить больше.

Проверка гипотезы 4

Таблица 9

Сравнение отношения мультипликатора Р/Е компании-покупателя к компании-цели для

\begin{tabular}{c|cc}
\multirow{2}{*}{ частных и публичных компаний } \\
& $\begin{array}{c}\text { Частная } \\
\text { компания- } \\
\text { цель }\end{array}$ & $\begin{array}{c}\text { Публичная } \\
\text { компания- } \\
\text { цель }\end{array}$ \\
\hline $\mathrm{P} / \mathrm{E}$ & $1,67 * * *$ & $1,15 * * *$ \\
относительное & 4, & \\
$t-s t$ & 4,6805 & 6,339
\end{tabular}

*** результат значим на 1\%-ном уровне

** результат значим на 5\%-ном уровне

* результат значим на 10\%-ном уровне

Как следует из таблицы 9, отношение мультипликаторов P/Е компании-покупателя к компании-цели выше при покупке частных компаний. Полученный результат может служить подтверждением того, что частные компании можно купить дешевле, и, возможно, по причине скидки за неликвидность.

Таблица 10

Результаты регрессии избыточной доходности на отношение мультипликаторов $\mathrm{P} / \mathrm{E}$ покупателя к Р/Е цели (в таблице представлены коэффициенты при переменной «отношение

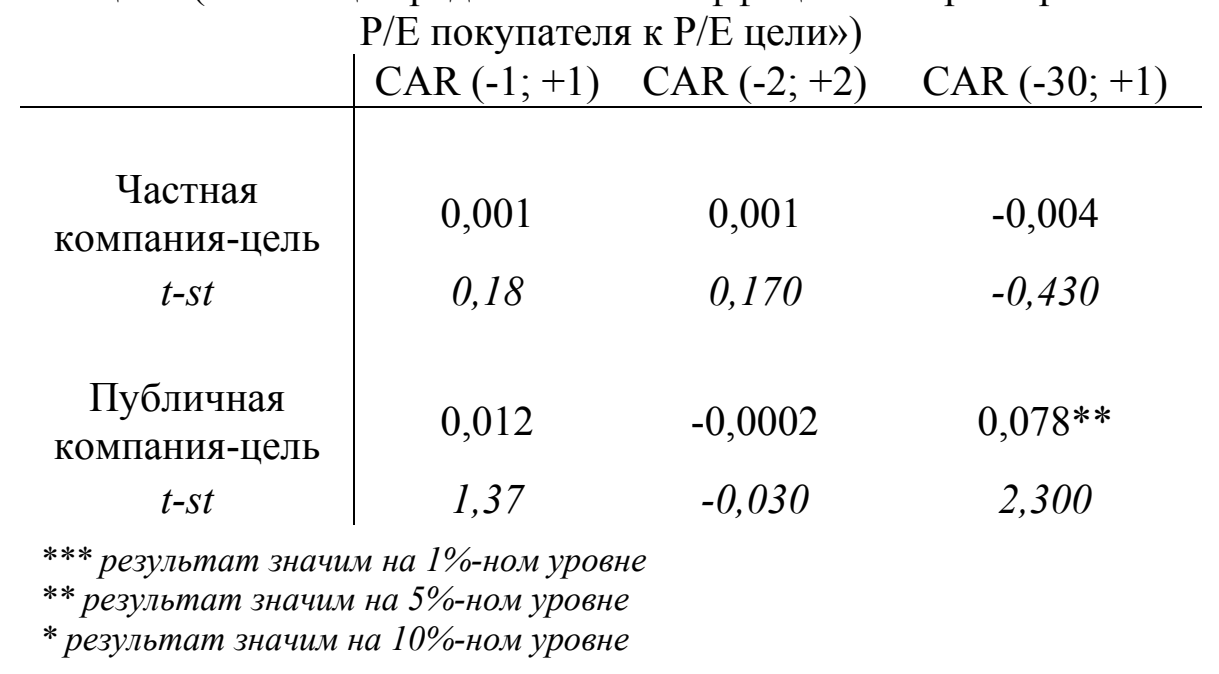

Из таблицы 10 видно, что явной зависимости между избыточной доходностью и ложной мотивацией компании-покупателя не наблюдается. Исключением является покупка публичной компании-цели, где в окне события $(-30 ;+1)$ рынок позволяет получить большую избыточную доходность при «натягивании» мультипликатора: превышение мультипликатора компании-покупателя мультипликатора компании-цели на 10\% позволяет получить прибавку к избыточной доходности в $0,78 \%$.

\section{Заключение}

В рамках настоящей работы проводилось исследование размера избыточной доходности и факторов, влияющих на нее, на выборке сделок с компаниями открытого и 
закрытого типов на развивающихся рынках капитала. Статистический анализ подтвердил результаты более ранних западных исследований, показав, что избыточная доходность при покупке частных компаний значимо положительна и статистически отлична от избыточной доходности покупателей публичных компаний.

Исследование показало более сильную положительную реакцию рынка на объявление о приобретении частной компании на развивающихся рынках, по сравнению с развитыми, и слабую отрицательную реакцию на объявление о приобретении публичных компаний. Данный результат может быть объясним большей волатильностью развивающихся рынков и, следовательно, более высокой требуемой доходностью инвестиций на данном рынке. Однако более реалистичным представляется альтернативное объяснение положительной реакции рынка как следствия меньшей конкуренции на рынке корпоративного контроля и, следовательно, меньшей переплаты за компанию-цель.

Регрессионный анализ показал, что в условиях отсутствия переплаты консолидация контрольного пакета положительно влияет на избыточную доходность покупателя. При этом она меньше в годы высокой активности рынка корпоративного контроля. Было подтверждено отрицательное влияние фактора диверсификации на избыточную доходность покупателя частной компании, что может объясняться, во-первых, реакцией рынка на большую асимметрию информации и, во-вторых, ожидаемыми рынком сложностями с дальнейшим управлением компанией, находящейся вне «круга компетенции» покупателя. На анализируемой выборке было подтверждено отсутствие существенной скидки за неликвидность при стратегических покупках.

Проверка зависимости избыточной доходности от фактора «переплаты» за компаниюцель выявила, что при покупке компании с меньшим по сравнению со среднеотраслевым мультипликатором P/Е избыточная доходность покупателя положительна и значима. Однако и в сделках с «переплатой» избыточная доходность имела положительный знак, что может свидетельствовать о способности рынка различать «хорошие» и «плохие» компании и не наказывать покупателя «хорошей» компании за уплату большей цены.

Эмпирическая проверка способности рынка отличить сделки с «ложной» мотивацией по «натягиванию» мультипликатора Р/Е от сделок с «правильной мотивацией» косвенно подтвердила возможность применения скидки при покупке частной компании.

Предметом дальнейшего исследования могут являться следующие вопросы: в чем сходство и различие реакции российского рынка и реакции рынков других развивающихся стран на объявление о сделке; на какие параметры сделок российский рынок реагирует особенно сильно, а какие не оказывают существенного влияния на волатильность цен акций компаний-покупателей. Ответ на эти вопросы позволил бы создать фундамент для поиска отличий в специфике рынка корпоративного контроля в России и других развивающихся странах.

\section{Список литературы}

1. Ang, J., Kohers, N. (2001), The take-over market for privately held companies: the U.S. experience, Cambridge Journal of Economics, 25 (2001) 723-748.

2. Berger, Ph. G., Ofek, E. (1995), Diversification's Effect on Firm Value, Journal of Financial Economics, 37(1) (1995) 39-65.

3. Bohl, M. T. and Pal, R. (2006), Discount or premium? New evidence on corporate diversification of UK firms, (2006): http://ssrn.com/abstract=900523.

4. Bradley, M., Sundaram, A. K. (2004), Do acquisitions drive performance or does performance drive acquisitions?, SSRN Working Paper:: http://ssrn.com/abstract=592761.

5. Capron, L., Shen, J.-C. (2007), Acquisitions of private vs. public firms: private information, target selection, and acquirer returns, Strategic Management Journal, 28(9) (2007) 891-911.

6. Chang, S. (1998), Takeovers of privately held targets, methods of payment and bidder returns, Journal of Finance, 53(2) (1998) 773-784. 
7. Conn, R., Cosh, A., Guest, P., Hughes, A. (2003), The impact on U.K. acquirers of domestic, cross-border, public and private acquisitions, Working paper № 276: http://www.cbr.cam.ac.uk/pdf/wp276.pdf.

8. Damodaran, A. (2005), Marketability and value: measuring the illiquidity discount: http://pages.stern.nyu.edu/ adamodar/pdfiles/papers/liquidity.pdf.

9. Draper, P., Paudyal, K. (2008), Information asymmetry and bidders' gains, Journal of Business Finance and Accounting, 35 (2008) 376-405.

10. Eckbo, E.B., Thorburn, K.S. (2000), Gains to bidder firms revisited: domestic and foreign acquisitions in Canada, Journal of Financial and Quantitative Analysis, 35(1) (2000) 1-25.

11. Faccio, M., McConnell, J. J., Stolin, D. (2004), Returns to acquirers of listed and unlisted targets: http://ssrn.com/abstract $=642063$.

12. Fauver L., Houston J., Naranjo A. (2003), Capital market development, international integration, legal systems and the value of corporate diversification: a cross-country analysis, Journal of Finance and Quantitative Analysis, 38(1) (2003) 135-157.

13. Fuller, K., Netter, J., Stegemoller, M. (2002), What do returns to acquiring firms tell us? Evidence from firms that make many acquisitions, The Journal of Finance, 57(4) (2002) $1763-1793$.

14. Jarrell, G. A., Poulsen, A. (1989), The returns to acquiring firms in tender offers: evidence from three decades, Financial Management, 18 (1989) 12-19.

15. Jensen, M. C. (1986a), Agency costs of free cash flow, corporate finance, and takeovers, American Economic Review, 76(2) (1986) 323-329.

16. Jensen, M. C. (1986b), The takeover controversy: analysis and evidence, The Midland Corporate Finance Journal, (1986).

17. Kohers, N. (2004), Acquisition of private targets: the unique shareholder wealth implication, Applied Financial Economics, 14(16) (2004) 1151-1165.

18. Lang, L. H.P., Stulz R. M. (1994), Tobin's Q. Corporate diversification and firm performance, Journal of Political Economy, 102 (1994) 1248-1280.

19. Mayers, S. C., Majluf, N. S. (1984), Corporate financing and investment decisions when firms have information that investors do not have, Journal of Financial Economics, 13 (1984) 187-221.

20. Moeller, S. B., Schlingemann, F. P., Stulz, Rene M. (2004), Do shareholders of acquiring firms gain from acquisitions?, Journal of Financial Economics, 73(2) (2004), 201-228.

21. Pratt, Sh.P. (2009), Business Valuation Discounts and Premiums. Second Edition. John Wiley \& Sons, Inc.

22. Roll, R. (1986), The hubris hypothesis of corporate takeovers, The Journal of Business, 59(2) (1986) 197-216.

23. Schwert, W. G. (1996), Markup pricing in mergers and acquisitions, Journal of Financial Economics, 41(2) (1996) 153-192.

24. Shliefer, A., Vishny, R.W. (2003), Stock market driven acquisitions, Journal of Financial Economics, 70 (2003) 295-311.

25. Villalonga, B. (2000), Does Diversification Cause the «Diversification Discount»? AFA 2001 New Orleans: http://ssrn.com/abstract=227828.

26. https://zephyr.bvdep.com/version-2008428/cgi/template.dll?product=24.

27. http://www.bloomberg.com.

28. http://www.capitaliq.com. 